\title{
Article
}

\section{Learning on the move: exploring work with vulnerable young men through the lens of movement}

\author{
Roy, Alastair Neil
}

Available at http://clok.uclan.ac.uk/18082/

Roy, Alastair Neil ORCID: 0000-0002-4807-7352 (2016) Learning on the move: exploring work with vulnerable young men through the lens of movement. Applied Mobilities, 1 (2). pp. 207-218. ISSN 2380-0127

It is advisable to refer to the publisher's version if you intend to cite from the work. http://dx.doi.org/10.1080/23800127.2016.1245097

For more information about UCLan's research in this area go to http://www.uclan.ac.uk/researchgroups/ and search for < name of research Group>.

For information about Research generally at UCLan please go to http://www.uclan.ac.uk/research/

All outputs in CLoK are protected by Intellectual Property Rights law, including Copyright law. Copyright, IPR and Moral Rights for the works on this site are retained by the individual authors and/or other copyright owners. Terms and conditions for use of this material are defined in the policies page.

\section{CLoK}

Central Lancashire online Knowledge www.clok.uclan.ac.uk

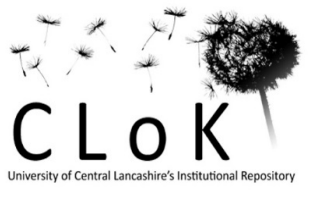




\section{Learning on the move: exploring work with vulnerable young men through the lens of movement}

\section{Alastair Roy}

To cite this article: Alastair Roy (2016) Learning on the move: exploring work with vulnerable young men through the lens of movement, Applied Mobilities, 1:2, 207-218, DOI: 10.1080/23800127.2016.1245097

To link to this article: http://dx.doi.org/10.1080/23800127.2016.1245097

曲 Published online: 16 Dec 2016.

Submit your article to this journal $\widetilde{ }$

Џ Article views: 23

Q View related articles $\widetilde{ }$

View Crossmark data $\nearrow$

Citing articles: 4 View citing articles 


\title{
Learning on the move: exploring work with vulnerable young men through the lens of movement
}

\author{
Alastair Roy \\ Psychosocial Research Unit, School of Social Work, Care and Community, University of Central Lancashire, \\ Preston, UK
}

\begin{abstract}
This paper discusses a practice context in which process and movement are central to the provision of care and support. It draws on data from a research project conducted with The Men's Room, Manchester, England which used ethnographic and mobile methods to explore the complex task staff undertake in engaging and supporting highly vulnerable young men. The organisation's commitment to getting alongside these young men includes a mobile and highly improvised use of temporary city centre spaces for delivering its work. In this paper, I argue that these movements of practice are not simply a logistical necessity or a physical activity, but involve a kinetic way of attending, reflecting, thinking and knowing in which the organisation's movements are intrinsic to the provision of care and support.
\end{abstract}

\section{ARTICLE HISTORY}

Received 29 September 2016 Accepted 3 October 2016

\section{KEYWORDS}

Mobility; mobile methods; men; care; practice

\section{Introduction}

I am an invisible man. ... I am a man of substance, of flesh and bone, fiber and liquids-and I might even be said to posses a mind. I am invisible, understand, simply because people refuse to see me. (Ellison 1952, 3)

Traditionally, research on social work and welfare practice has shown little interest in mobilities. However, recently, and informed by the mobilities paradigm, some academics have begun to theorise and conceptualise social work and welfare practice through the lens of movement (Ferguson 2008, 2010a, 2010b, 2014; Hall and Smith 2013; Roy et al. 2015). Harry Ferguson's (2008) work is a good example. In it, he seeks to understand the daily lives of movement of social work practitioners (including the sights, smells, feelings and affects of practice) offering a distinctive lens on child protection social work. This allows him to develop arguments about the place and function of movement in allowing social work practice to happen (Ferguson 2008, 2010a, 2010b). What we come to appreciate through this and other work is that movement in practice is not simply a physical or behavioural activity ("a means to transport the brain from one place to another $\left.{ }^{\prime \prime}\right)$, but is a kinetic way of thinking and knowing (Roy et al. 2015), an activity done through the feet (Ingold 2010). In this paper, I

CONTACT Alastair Roy anroy@uclan.ac.uk 
explore the movements of a group of practitioners working with vulnerable young men in Manchester. The mobile practices of the organisation respond to the movements of the young men as they experience and know the city. This can make these two different forms of movement hard to disentangle from one another, because one responds to the other. However, in the discussion I try to focus on the ways in which these movements of practice and practitioners are central to the delivery of a relational and embodied form of practice and hence to the provision of care and support. I begin by introducing the theoretical and conceptual ideas I refer to throughout, after which I introduce the organisation in which the research took place and describe elements of the methodology.

In Being Alive: Essays on Movement, Knowledge and Description, Ingold (2010) discusses a set of epistemological and methodological ideas which are well documented in the mobilities literature. These concern questions about the possibilities of knowledge making as well as questions about how knowledge might be made. Ingold (ibid., S122) suggests ...

If knowledge is indeed made, then making has to be understood in the sense implied when we say of people that they "make their way" in the world. It is not a construction, governed by cognitive mechanisms of one sort or another, but an improvisatory movement - of "going along" ... that is open-ended and knows no final destination.

In this work Ingold (2010,153-155) develops an analogy which I paraphrase for the purposes of this paper. He develops this through a story about a team of scientists who set out to investigate the ecology and hydrology of an Arctic tundra in a particular region of the Russian North. The scientists draw a straight line on a map of 20 locations (identified by dots on the map $1 \mathrm{~km}$ apart) from which they want to collect samples. They use a helicopter to travel from place to place, in a literal re-enactment of the drawing of the dotted lines on the map. The movement from place to place is ancillary to the primary task of data collection, which happens only at the fixed locations. These locations represent, not a pathway, but a chain of point-to-point connections. Ingold compares the scientist's approach to knowledge making, to the ways in which the helicopter pilot - who transports them from place to place accumulates the knowledge she employs. Unlike the visiting scientists, the helicopter pilot knows the terrain and how to find her way across it. This knowledge is not derived from the locations, but comes from a history of making similar flights and of the incidents and encounters which constitute these. This knowledge is forged in movement in the "passage from place to place" (Ingold 2000, 227).

The relevance of this story to this chapter is that through it Ingold (ibid., S134) argues that knowledge is not built up and established in situ, but "grows along the paths" we take in the world. One can see this in Hall and Smith's $(2013,1)$ research conducted with homeless outreach workers in Cardiff. The authors describe how the workers are "experts in the terrain in which they operate", describing a research interest in how it is, and through which methods, that welfare workers arrive at the knowledge they exercise in their practice (3). These concerns relate to Ingold's ideas, because they suggest that the expertise of these practitioners is built in and through movement. In other writing about streetwork, Sennett (2003) is interested in understanding the sharply honed skills of those workers capable of working with "the most difficult cases" (sic). He describes how streetworkers must accumulate contextual knowledge in a community of practice over many years. What the work of Ferguson, Hall and Smith and Sennett all in different ways suggest is that welfare practice is predicated on a form of corporeal and embodied knowledge which is built in the environment and through movement (O'Neill 2014). So, practitioners don't apply knowledge learned elsewhere in the 
practice context, but come to know along the way and by way of their practice (Ingold and Kurtilla 2000, 191, 192).

Ingold $(2011,161)$ extends this line of thought in making a distinction between the knowledge characteristics of the expert and the novice. He says ...

To be sure, the expert is more knowledgeable than the novice. What distinguishes them, however, is not a greater accumulation of mental content - as though with every increment of learning yet more representations were packed inside the head - but a greater sensitivity to cues in the environment and a greater capacity to respond to these cues with judgement and precision. The difference, if you will, is not one of how much you know but how well you know.

In social work and welfare, how well practitioners know is central to the realisation of good practice. Hence, the expert practitioner - through greater sensitivity to cues in the environment and greater capacity to respond to the cues with judgement and precision - is more capable of developing an intersubjective space of exchange. This necessarily directs our attention to the relational affordances of movement in welfare practice, or to put this another way, that movement is one means by which people are able to work productively together. Hence, in this paper, I will explore the ways in which movement helps to create the communicative and relational rhythms of practice, which I argue significantly affect the possibilities of working productively with vulnerable young men (Wotton 2012). In the existing mobilities literature, these ideas are not currently well developed. However, the research of Ferguson, and Hall and Smith, helps us to appreciate that the ways in which practitioners move (or fail to) through the psychosocial and spatial environments of practice significantly influence the possibilities of understanding and responding to the needs of those they are professionally responsible for. Hence, the argument I develop is that movement is a mode of experiencing the spaces of practice and a particular way of engaging with the lifeworlds of those who inhabit them (Lee 2004, 1). In the case of the organisation I discuss in this paper, I argue that this movement offers the possibility of bringing a group of vulnerable young men into visibility and recognition, allowing the delivery of caring encounters.

The paper is based on research conducted with the Men's Room, an arts and social welfare organisation working with vulnerable young men in Manchester, England. The young men, who access the service voluntarily, commonly share experiences of being looked after by the state, alcohol and drug use, mental health problems, educational failure and involvement in crime and most are not living in secure accommodation. At the time of writing, approximately 45 young men attend the project regularly. The Men's Room delivers two creative sessions each week delivered in collaboration with artists and also delivers outreach sessions and mobile streetwork.

The research is written up in detail elsewhere (Hughes, Roy, and Manley 2014; Roy et al. 2015; Manley and Roy 2016). The methodology included a years ethnographic participant observation (Spradley, 1980) and a visual method employed with staff and volunteers (Manley and Roy 2016). We also used walking tour interviews with seven young men who were in contact with the Men's Room. I won't engage in a detailed discussion about our motives for using mobile and visual methods in this paper, because I have written about this elsewhere (Roy et al. 2015; Manley and Roy 2016). Briefly, however, our particular motives for using walking tours were twofold: first, they were driven by a recognition that walking affords a form of embodied knowing built through movement (O'Neill 2014) and this reflects important aspects of the practice context; and second, that walking might afford a means to understand how the young men's identifies were built in relation to their lives and 
movements through the city (Pink 2007). The methodology developed reflects contemporary interest in mobile and visual methods (and their combination) across a number of disciplines, which include anthropology and ethnography (Pink 2007, 2008; Ingold and Vergunst 2008), cultural geography (Anderson 2004) and qualitative social science (Ferguson 2008, 2010a, 2010b; Hall 2009; Hall and Smith 2013; O’Neill 2014).

\section{Young men on the move - (in)visibility and (dis)connection}

In this research, we invited the young men to lead a walking tour of city centre sites they associated with their own "survival"2. On the tours we walked and talked side by side with the young men through the city and on arrival at each stop, we asked the men to take a photograph and, if they were happy to, tell a story about the site. The seven walking tour interviews provided us with different stories of how the young men lived and moved through the city in their daily lives. For the purposes of this paper, I draw on short excerpts from two of the tours which are emblematic of the ways in which the young men drew on their relationships with the city in constructing a sense of themselves, their pasts, presents and futures (Back 2007).

One is provided by a walking tour led by a young man we call Josh (not his real name). Josh begins the tour near Piccadilly Gardens in the centre of Manchester. He starts by describing how his father and grandfather were both builders, saying they worked on some of the "major construction projects in Manchester". Through this story he seems to want to secure a sense of his own history in relation to the city and it's buildings. If you sit in Piccadilly Gardens you can see buildings from different eras around this central park. Josh's story brings to mind the histories of labour that have gone into these buildings and the ways in which individual working biographies are invisibly sedimented within the physical structure of the city. However, his story also brings his own unemployment into view, marking out how family traditions of working have been eroded for so many young men in the last 30 years.

Shortly afterwards is the first stop on the tour, which is a multi-storey car park in Manchester's Northern Quarter district. This is the city's old cloth district and is now filled with fashionable bars and clothes shops, and is also a place where homeless people often congregate. Josh describes how he used to sell drugs at the car park and now tries to stay away. Walking into the entrance he says that multi-storey car parks of the city provide safe, undisturbed places to use drugs and easy access to opportunities for theft. He leads the way to the seventh floor and takes a picture of the asphalt roof pointing out the used syringes that cover the floor. Here, Josh offers a commentary on his views and experience of the city, saying ...

No-one's like "where are all these crack heads going, where are all the smack heads, where are all the homeless going to drink the beer?" Going down canals? Because you don't really find them down canals no more. You find them in dingy, dark places, you find them in places where people keep valuables, you find them in all sorts of places. You find them up in your face and you don't even realise ... Well my, my expression of things, like I said, it's twisted. ... You get these people and they, they only see things the way you're told to see them. And you're told to see certain things. Whereas me, what I'm told to see, I've got my own eyes, I can do what I want.

In the interview, Josh leads a tour of a world that he describes as beyond the eyes, ears and interests of society. He suggests there is increasing disinterest amongst authorities and publics in what happens in certain spaces and places in the city and goes on to talk about 


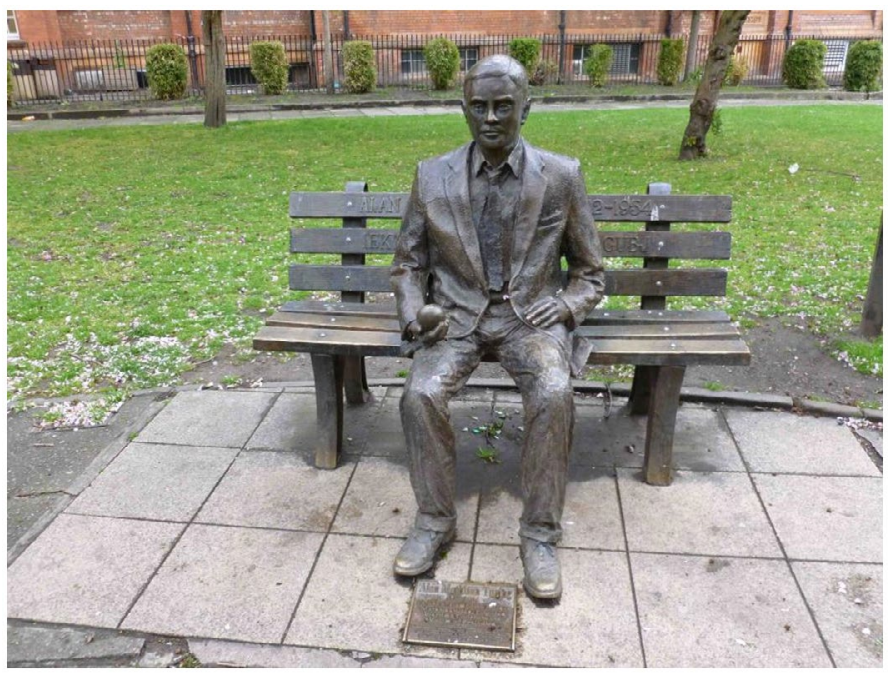

Figure 1. Alan Turing statue, Sackville Gardens.

the ways "you're told to see certain things" and how he's got his "own eyes". His descriptions focus on notions of visibility and invisibility, what is seen and unseen by different people. The word "twisted" is both expressive and ambivalent in the above quote. He describes a certain self-respect which he takes from taking his own twisted view of society, and also describes how by developing his own personal day-to-day practice of looking, listening, attending and acting he has been able to find a way through, to manage the city's most urgent risks and to gain a certain kudos from his peers by doing so.

A second tour is led by a young man we call Jeff. Jeff's behaviour has regularly got him into conflicts with other people, leading to a series of arrests and prosecutions as well as difficulties with staff and other young men at the Men's Room. In the tour, he takes in two spaces in the city, describing the ways in which these provide him with important moments of containment and reflection, as well as a sense of companionship (Figure 1). The first site - the Alan Turing statue in Sackville Gardens ${ }^{3}$ - was a place that Jeff could sit in the company of another:

It's where I come. Some people think I'm mad because I sit talking to him. But he gets my head straight ... He don't pass judgment, that's the one thing. ... I used to sleep in the car park over there and then in the day time l'd come and sit here and then just talk to Alan. Sometimes it was like, he was the only one that listened, at one point.... And then even just sitting here, watching things go past you're not on your own because you got someone sat next to you. And yeah, looks a bit creepy but it's, sometimes it's all you need, someone that's just there.

This tour brings to mind just how striking and unusual the statue of Alan Turing is, because, instead of casting you in the role of viewer, its physical design invites you to become a companion, take a seat beside him, to watch the world go by, and perhaps to share some thoughts with him as Jeff chooses to. Sackville Gardens is in the heart of Manchester's Gay Village and as you look to the right you can see the bright lights of bars, restaurants and clubs on Canal Street and often hear the chatter of people on the street and the four-four beats of dance music emerging from the numerous bars and clubs. As you gaze to the left you see the main road linking two of Manchester's train stations and beyond it the buildings of Manchester 
University in which the computer pioneer took the first groundbreaking steps towards the development of today's "artificial intelligence" (Cooper 2013). Jeff, who identifies as gay, is aware of the suffering caused to Alan Turing in his own life through homophobia. By leading a tour to the statue of this gay man long since dead, Jeff introduces us to a space in which he can share his thoughts in the company of another who helpfully does not answer back or intervene.

A feature of Jeff's tour is that he introduces us to a series of his daily "practices" (Gunaratnam 2015, 6; cites Bourdieu 1990). These practices (as Pierre Bourdieu imagined it) involve an improvised, bodily know-how and a sensual capacity to "habiliment" which in Jeff's case he uses to expertly navigate the challenges of surviving in the city. Jeff takes us to places in which he can retain a connection with the social world in a way that feels safe. The concrete and metal facades of the city provide moments of relief and respite, providing Jeff with important spaces in which he is able to contain his destructive feelings. However, they also perhaps reproduce a sense of just how disconnected he is from social and familial networks of support.

Taken together the seven tours completed in the research open out a series of personal practices of looking, attending and moving through the city (Hughes, Roy, and Manley 2014). These point to some of the contradictions of visibility and invisibility for marginal populations as well as providing a sense of how young men like Josh and Jeff must develop their own forms of expertise in order to know well enough to get by. However, the lives and stories of these young men pose difficult and pressing questions about how services might know well enough to be able to provide relevant support. In the next section, I develop this line of thought by looking at the Men's Room's approach through the lens of movement.

\section{Work on the move - visibility and recognition}

In one element of the original research we used a visual and associative research method (The Visual Matrix, Froggett, Manley, and Roy 2015) to encourage staff and volunteers to relate to their work, in an attempt to access thoughts and feelings about it that might lie "beneath the surface" (Clarke and Hoggett 2009). During one of the sessions in this work, one participant drew the following image (Figure 2).

The image clearly conveys elements of the built environment of the city as well as capturing aspects of the ways in which young men move through the city. It includes a series of ghost-like figures who are partially seen. In the image, the routes that young men trace through the city are ones which seem to cut across the straight and deliberate lines of the built environment. Many of the figures appear to be on the move, they are often half in and half out of buildings, or peering watchfully from spaces above the ground. One figure lies prone on the floor of a multi-storey car park and its unclear whether he is resting, injured or perhaps dead. In the ensuing discussing, one member of staff described how the young men appeared to have these magical abilities to trace routes through the city centre and to disappear and reappear. Hence, the image captures both the known realities of the young men's lives as well as some of the fantasised relations that staff members have about the ways in which the young men inhabit and move through the city. As I described previously, the lives of the young men are characterised by movement, as they sofa surf, find a temporary base, outstay their welcome, fall out with friends and family, and wander into and out of scenes of crime, threat and opportunity. Hence, the image offers an interpretive reflection 


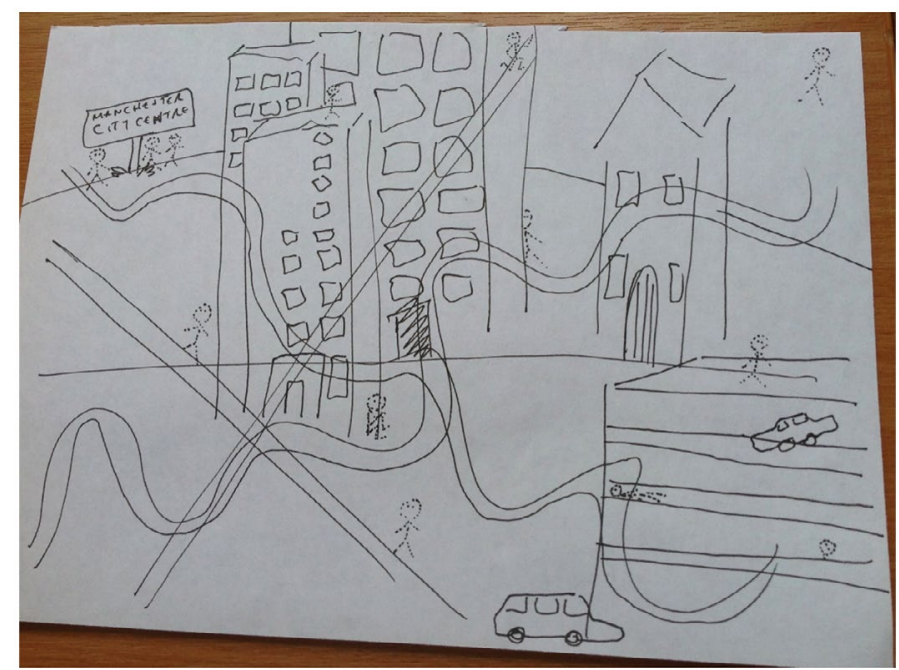

Figure 2. Image drawn in Visual Matrix.

of the relationship between the young men and the city, one which hints at a wider set of ideas held by staff who must live with the vulnerability of the young men's lives and who must define an appropriate approach in working with them (Manley and Roy 2016).

One element of the practice approach of the Men's Room is that it attempts to realise its work in spaces that are accessible and acceptable to the young men it seeks to support. This involves an explicit commitment to continue to move through the city in delivering outreach support, as well as moving the sites of the drop-in and creative-sessions in response to the young men's shifting situations and needs. In recent years, it has delivered its weekly sessions in spaces which have included a tent erected in a street, a barbers shop, a local LGBT centre, a teaching room in a college, a homeless support project, a drug and alcohol treatment service, a theatre space, an arts café and various church spaces. All of these temporary sites are in the city centre and within less than a mile of each other and yet, at different points in time, each of them has been off-limits to some of the young men. This is because the young men are subject to-both formal and informal-proscriptions of space and many must manage explicit visibility and absolute invisibility in places which are incredibly close together. For example, some have to report in to the Probation Service in a building in the city centre at a specific time as part of criminal justice orders, but also have Anti Social Behaviour Orders whose conditions prohibit their presence in postcode areas close by. Some are selling sex in a specific location, but are also avoiding areas only a street or two away for reasons of personal safety. Hence, the demand to "move on" shapes the daily experience and life histories of many of the young men, whose personal cartographies are highly fluid, reflecting the ways in which their situations shift unpredictably and quickly both through their own behaviour, through the impersonal actions of systems of care and control, and the anticipated and unanticipated actions of friends, families and others.

In the course of the research, the then Creative Director of the Men's Room said to us, "It may well be that we always have to be moving". At the time I thought about this comment mainly in terms of the continual movement of practice settings from one temporary location to another, essentially seeing it as a practical concern. It's clear that the practical elements 
of movement are vital in allowing some young men to continue to take part in the work, just as the outreach work (in which staff walk routes through the city centre to allow for deliberate and accidental encounters with young men in need of support) is vital in making and maintaining contact with men. However, returning to Ingold's (2010) story about the scientists and the helicopter pilot provides a different way of interpreting the Creative Director's comment. One way of viewing the work of the Men's Room is that, despite moving from site to site, the workers are more like the scientists in Ingold's story, with the real work happening in each location. This would view the movement as necessary but ancillary the main task of delivering care and support to vulnerable young men. The other view is that the workers have more in common with the helicopter pilot. As they move around the city in the course of their work, they come to "know their patch" (Hall and Smith 2013, 3), and through this movement they generate their practice knowledge (i.e. not to know more but to know better (Ingold 2010, 161). The practices of the Men's Room demonstrate that these movements - of workers and practice locations - allow acts of recognition to take place, bringing the young men into visibilility, literally and metaphorically. Viewed in this way, the comment from the Creative Director might be seen as clarifying how the movements of staff are critical to the realisation of a relational and dialogic practice. By moving through the city, workers are able to build knowledge about the lives, situations and needs of the young men and through a continued commitment to the delivery of small and frequent acts of care are able to continually re-formulate a basis for working productively together in conditions of extreme uncertainty (Hall and Smith 2014).

In the course of the research project, one of the young men said to me one evening, "this is the only place I come all week where I feel normal". As Janet Batsleer (2011) has observed, this might be partly because the Men's Room's approach gives these vulnerable young men the permission to do normal things like going for a walk, playing, meeting in a café, having fun, cooking and eating a meal together, providing support to each other and having a laugh. Access to these normal experiences provides a vital sense of connection and attachment to the world, even if just for a few short hours a week. This is so important for reasons we come to understand in the walking tour with Jeff, when he conveys how he often uses the built environment of the city to maintain this sense of connection to the wider world. It seems possible that in many of the spaces in which young men like Jeff live, as well as in the places in which they receive services, that people simply fail, or refuse, to see them (Sander, 1995 cited in Orange 2010). As the work of Goffman (1968) and Sennett and Cobb (1993) documents so starkly, this withholding of recognition means many working-class men must carry the - always embodied - subjective residues of stigma. These residues are often inscribed on the bodies of young men at the Men's Room (Frost and Hoggett 2008), many of whom are visibly underweight (sometimes severely), poorly clothed (despite attempts to maintain a status through appearance) and most are unable to wash regularly, have missing teeth and facial scars. However, the mobile practices of the Men's Room literally and metaphorically bring these men into visibility and recognition. Hence, the movements are a vital prerequisite to these young men being able to accept support from staff and when they are ready, for the young men to begin to develop their own particular ways of accepting, changing and/or learning to live with their situations (Spandler and Stickley 2011). 


\section{Discussion - moving and knowing}

Approaching the practices of the Men's Room through the lens of movement opens out a set of important considerations about the knowledge-based and relational affordances of the modes of movement exhibited by workers. The men who use the project have very complex needs. To the extent that they register on the radar of mainstream society, they generally do so as problems. Many of them are in their mid to late 20s, and they often feel a powerful and shameful personal sense of failure (Goffman 1968). They are a very difficult group to work with and whilst they sometimes demonstrate concern and care for themselves and others, they more often present as aggressive, resentful and suspicious, directing their hurt and loss at others, including each other (Frost and Hoggett 2008). I saw this myself in the research in which I witnessed several occasions in which men subjected each other to vindictive and shaming verbal attacks, often on the flimsiest pretext.

Hall and Smith (2014) and Scanlon and Adlam (2008) refer to the tensions that inhere in working with those on the extreme margins, such as the street homeless. Politicians, commissioners and councillors often want these people "fixed" (Hall and Smith 2014, 12), delivered from $A$ to $B$, ideally in as short a time as possible. In the era of payment by results commissioning, social welfare agencies are increasingly paid on the basis of whether or not they can evidence their success in delivering these measurable social outcomes. However, the apparent refusal of help exhibited periodically by people in these situations makes the task of working with them even more complex because as well as being excluded they also seem to exclude themselves (Frosh 2001; Scanlon and Adlam 2008).

As we see in the walking tour interviews, disconnected and phobic about reaching out to other people, for many of these men, surviving has involved developing highly idiosyncratic "practices" of looking, moving and attending which become intrinsic to their sense of self, as well as the style of service provision that they might be prepared to engage with (Roy et al. 2015). It is for these reasons that the movements of the men who use the Men's Room project often seem to cut across the organised grids of the city. However, somewhat ironically, it is sometimes the physical environment of the city - rather than other people - that provides these men with experiences of containment, respite and release. So car parks become spaces to rest and relax, statues provide opportunities to watch and converse with another, and public parks become spaces to feel a sense of connection to the wider world without the risks of engaging with movable and moving people. In this way, the young men's movements through the city are both "purposive" and "discursive" (Rendell 2003, 231) and they reflect a complex reality that seems to embrace a desire to be visible (seen and recognised) in conditions in which it is often functionally necessary to be invisible and in which the men suffer both from a lack of recognition (from services and society) and acts of misrecognition (from many people). By being invisible, the men are able to slip unnoticed through the city, they are able to avoid surveillance and enjoy a form of power, agency, identity and recognition from each other. This is captured in the image drawn by the staff member, where the ghostly figures moving around the city sit somewhere between visibility and invisibility.

Responding to the - psychic and physical - movements of the young men is a source of a good deal of anxiety for staff at the Men's Room. Choreography might be the most appropriate way of describing the movements of staff, who must learn to operate in response to the young men's complex movements and webs of meaning. The mobile impulse of the organisation consistently works to engage the young men within their own frame of 
reference, taking seriously their current situations, their experiences, their emotional lives, sense of humour as well as their imaginations. The challenge of these forms of practice is that staff must hold and work with this uncertainty as they constantly attend to and respond to the men's changing situations. To return to Ingold, what the staff at the Men's Room come to learn about and through their practice, is not "governed by cognitive mechanisms of one sort or another, but involves an improvisatory movement - of 'going along' ... that is openended and knows no final destination" (Ingold 2010, S122). For all its uncertainty, the benefit of this approach is that the Men's Room becomes a site of engagement and recognition, which is vital for a group of young men pushed to the extreme margins of society.

The movements of staff and practice locations at the Men's Room are a key way in which staff become "experts in the terrain in which they operate" (Hall and Smith 2013, 1). This terrain is both physical (the built environment) and relational (the lives and situations of the men). Hence, the practices of the Men's Room allow staff to work up a form of corporeal and embodied knowledge which must continually be (re-)developed in the environment and through movement (O’Neill 2014). The comment made by the Creative Director ("It may well be that we always have to be moving".) communicates the ways in which movement supports a commitment to hold in tension two different temporalities identified by Gunaratnam (2015, 160 ), balancing the vital need for immediate action (to move through the terrain of the city and to foster relations in the present), with a patient attention to a future which lies over the horizon but which they must still care about (emphasised by an approach to practice which involves patiently attending to the emotional lives of the young men as well as their own personal strategies for dealing with their situations).

The work is especially difficult in the current climate, because structural factors severely inhibit the likelihood that many of these men will ever attain even the most basic forms (and feelings) of inclusion (Frosh 2001; Manley and Roy 2016). In fact, a number of young men accessing the service have taken their own lives over the years, and what is especially hard for staff and volunteers is that these deaths have sometimes happened when the young men seemed to be most engaged in projects of personal change and appeared to be doing particularly well. The reality is that for many of these men, efforts to "move on" can involve engaging with the depressing realisation of just how marginal and excluded they are. For many practitioners, it is the recognition of the young men's continued suffering as well as the social injustices which sustain it, that "fuels their anger" and "sustains their commitment to the work" (Hoggett, Mayo, and Miller 2006). However, staff also find that defending the work in a commissioning climate driven by notions of fixing is especially hard. The fear is that maintaining the commitment to work in this mobile and provisional manner may eventually be perceived as too difficult to defend. As Hall and Smith $(2014,9)$ point out "Social repair is another 'infrastructure of kindness' ... And perhaps we would notice this work rather more than we ordinarily do, and before too very long at all, if suddenly everyone stopped doing it".

\section{Notes}

1. This paraphrases Ken Robinson's Ted Talk on how schools kills creativity http://www.ted.com/ talks/ken_robinson_says_schools_kill_creativity?language=en.

2. A theme the young men chose to engage with in the research.

3. Alan Turing was a mathematician and computer scientist. He worked at Bletchley Park in Buckinghamshire during the Second World War, developing code-breaking methods, and from 
1949 for the University of Manchester, where he helped develop the first computer. In 1952, Turing admitted to a sexual relationship with another man (illegal in the UK at the time) and was convicted of gross indecency. His conviction ruined his reputation and on 8 June 1954 he killed himself by eating an apple poisoned with cyanide. Alan Turing received a posthumous Royal Pardon in 2013.

\section{Acknowledgements}

Huge thanks go to all the young men who shared elements of their lives and experience with us in the course of the research - they must remain anonymous, but without them the work would be impossible. Thanks to Lankelly Chase Foundation which funded the research and to all staff and volunteers at the Men's Room for their support, collaboration and care. Special thanks to Chris Charles for his generosity and the numerous ways in which he has supported the work and the discussions and presentations that led to this paper. Thanks to Jenny Hughes, Kate McCoy and Julian Manley who also contributed to the original research, and to George Dake for more recent conversations about the Men's Room based on his own research. And last, but not least, thanks to Les Back and journal reviewers for commenting on earlier drafts of this paper.

\section{Disclosure statement}

No potential conflict of interest was reported by the author.

\section{Funding}

This work was supported by the Lankelly Chase Foundation.

\section{References}

Anderson, J. 2004. Talking whilst walking: A geographical archaeology of knowledge. Area 36, no. 3: 254-61.

Back, L. 2007. The art of listening. London: Bloomsbury.

Batsleer, J. 2011. Voices from an edge. Unsettling the practices of youth voice and participation: Artsbased practice in The Blue Room, Manchester. Pedagogy, Culture and Society 19, no. 3: 419-34.

Batsleer, J., and J. Hughes. 2014. Looking from the other side of the street: Youth, participation and the arts in the edgelands of urban Manchester. In Design in the borderlands, eds. Tony Fry and Eleni Kalantidou, 156-173. London: Routledge.

Bourdieu, P. 1990. The logic of practice. Cambridge: Polity.

Clarke, S., and P. Hoggett. 2009. Researching beneath the surface: A psycho-social approach to research practice and method. In Researching beneath the surface, eds. S. Clarke and P. Hoggett, 1-26. London: Karnac.

Cooper, B. 2013. Alan turing year - The establishment still doesn't get it. http://www.theguardian.com/ uk/the-northerner/2013/jan/22/alan-turing-computing.

Ellison, R. 1952. Invisible man. London: Penguin.

Ferguson, H. 2008. Liquid social work: Welfare interventions as mobile practices. British Journal of Social Work 38: 561-79.

Ferguson, H. 2010a. Walks, home visits and atmospheres: Risk and everyday practice and mobilities of social work and child protection. British Journal of Social Work 40: 1100-17.

Ferguson, H. 2010b. Therapeutic journeys: The car as a vehicle for working with children and families and theorising practice. Journal of Social Work Practice 24, no. 2: 121-38. doi:10.1080/02650531003741553.

Ferguson, H. 2014. Researching social work practice close up: Using ethnographic and mobile methods to understand encounters between social workers, children and families. British Journal of Social Work 46, no. 1: 153-168. Advance Access published November 7, 2014. 
Froggett, L., J. Manley, and A. Roy. 2015. The visual matrix method: Imagery and affect in a group-based research setting. FQS 1-31. http://www.qualitative-research.net/index.php/fqs.

Frosh, S. 2001. Psychoanalysis, identity and citizenship. In Culture and citizenship, ed. N. Stevenson, 62-73. London: Sage.

Frost, L., and P. Hoggett. 2008. Human agency and social suffering. Critical Social Policy 28, no. 4:438-60. Goffman, I. 1968. Stigma: Notes on the management of spoiled identity. Harmondsworth: Pelican.

Gunaratnam, Y. 2015. Death and the migrant: Bodies, borders and care. London: Bloomsbury.

Hall, T. 2009. Footwork: Moving and knowing in local space(s). Qualitative Research 9, no. 5: 571-85.

Hall, T., and R. Smith. 2013. Knowing the city: Maps, mobility and urban outreach work, in Qualitative Research, online first http://qrj.sagepub.com/content/early/2013/01/23/1468794112469623.

Hall, T., and R. Smith. 2014. Care and repair and the politics of urban kindness. Sociology, online first. http://soc.sagepub.com/content/early/2014/09/29/0038038514546662.

Hoggett, P., M. Mayo, and C. Miller. 2006. The dilemmas of development work. Bristol: Policy Press.

Hughes, J., A. Roy, and J. Manley. 2014. Surviving in Manchester: Narratives on movement from the Men's rooms, Manchester. London: Lankelly Chase Foundation.

Ingold, T. 2000. The Perception of the environment: Essays on livelihood, dwelling and skill. London: Routledge.

Ingold, T. 2011. Being Alive: Essays on Movement, Knowledge and Description. London: Routledge.

Ingold, T., and T. Kurtilla. 2000. Perceiving the environment in Finnish Lapland. Body and Society 6, no. 3/4: 193-196.

Ingold, T., and J. L. Vergunst, eds. 2008. Ways of walking: Ethnography and practice on foot. Hampshire: Ashgate.

Lee, J. 2004. Culture from the ground: Walking, movement and placemaking. Paper presented as the Association of Social Anthropologists Conference, Durham. http://www.abdn.ac.uk/anthropology/ WrittenPapers.php (accessed October 20, 2005).

Manley, J., and A. Roy. 2016. The visual matrix: A psycho-social method for discovering unspoken complexities in social care practice. Psychoanalysis Culture and Society.

O'Neill, M. 2014. Participatory biographies: Walking, sensing and belonging. In Advances in biographical methods: Creative applications, eds. M. O'Neill, B. Roberts, and A. Sparkes, 73-89. London: Routledge.

Orange, D. 2010. Recognition as: Intersubjective vulnerability in the psychoanalytic dialogue. International Journal of Psychoanalytic Self Psychology 5: 227-43.

Pink, S. 2007. Walking with video. Visual Studies 22, no. 3: 240-52.

Pink, S. 2008. Mobilising visual ethnography: Making routes, making place and making image. Forum Qualitative Sozialforschung/Forum: Qualitative Research 9, no. 3. http://www.qualitative-research. net/index.php/fqs/article/view/1166.

Rendell, J. 2003. A place-between, art, architecture and critical theory. In Place and location; studies in environmental aesthetics and semiotics III, eds. V. Sarapik and K. Tüür, 221-233. Tallin: Proceedings of the Estonian Art Academy.

Roy, A., J. Hughes, L. Froggett, and J. Christensen. 2015. Using mobile methods to explore the lives of marginalised young men in Manchester. In Innovations in social work research, eds. L. Hardwick R. Smith, and A. Worsley, 153-170. London: Jessica Kingsley.

Sander, L. 1995. Identity and the experience of specificity in a process of recognition: Commentary on Seligman and Shanok. Psychoanal. Dial. 5: 579-593.

Scanlon, C., and J. Adlam. 2008. Refusal, social exclusion and the cycle of rejection: A cynical analysis? Critical Social Policy 28, no. 4: 529-49.

Sennett, R. 2003. Respect: The formation of character in an age of inequality. London: Penguin.

Sennett, R., and J. Cobb. 1993. The hidden injuries of class. London: Faber and Faber.

Spradley, J. 1980. Participant observation. London: Holt, Rinehart and Winston.

Spandler, H., and T. Stickley. 2011. No hope without compassion: The importance of compassion in recovery-focused mental health services. Journal of Mental Health 20, no. 6: 555-66.

Wotton, L. 2012. Between the notes: A musical understanding of change in group analysis. Group Analysis 46, no. 1: 48-60. 